\title{
Energy Drinks Consumption amongst Medical Students and Interns from Three Colleges in Jeddah, Saudi Arabia
}

\author{
Nahla Khamis Ragab Ibrahim ${ }^{1,2, *}$, Rahila Iftikhar ${ }^{1}$, Manal Murad ${ }^{1}$, Hashim Fida ${ }^{1}$, Bahaa Abalkhaeil ${ }^{1}$, \\ Jawaher Al Ahmadi ${ }^{1}$ \\ ${ }^{1}$ Family and Community Medicine Department, Faculty of Medicine, King Abdulaziz University, Jeddah, Saudi Arabia \\ ${ }^{2}$ Epidemiology Department, High Institute of Public Health, Alexandria University, Alexandria, Egypt \\ *Corresponding author: nahlakhamis@yahoo.com
}

Received April 01, 2014; Revised May 09, 2014; Accepted May 09, 2014

\begin{abstract}
Background: Consumption of energy drink represents an escalating global public health problem especially among adolescents and young adults. Energy drink contains stimulants mainly caffeine that marketed as mental and physical stimulator although there are many safety concerns against use. Objectives: To determine the prevalence, pattern and predictors of energy drink consumption among medical students and interns in medical colleges, Jeddah, Saudi Arabia. Materials and methods: A cross-sectional study was conducted at three medical colleges (the governmental medical college of King Abdulaziz University and other two private colleges). A multistage stratified random sample technique was used with selection of 610 medical students \& interns. Data was collected using a validated, confidential \& self-administered questionnaire. SPSS version 21 was used for statistical analysis. Results: More than one-half of the participants (52.6\%) had "ever" tried energy drinks, while 33.4\% consumed it regularly during the two months preceded the study. Friends, advertisement and curiosity were the inspirations for starting. Among regular users, the commonest reasons for consumption were enjoying leisure time with friends (57.5\%), boosting energy for studying (56.4\%), and staying awake for long hours (50.5\%). However, $31.6 \%$ of regular energy drinks consumers experienced adverse effects as palpitation, insomnia and frequent micturition. In bivariate analysis, regular consumption of energy-drink was significantly associated with male gender, students from private colleges and smokers. After controlling of confounding factors smoking was the only predictor of energy drinks consumption (aOR= 3.68; 95\% CI: 2.36-5.71). Conclusion: Consumption of energy drinks is rather common among medical students and interns despite of high prevalence of adverse effects. Smoking is the most important predictor. Implementation of educational awareness campaigns, especially in medical colleges, about healthy dietary habits, potential benefits, side effects and correction of wrong perceptions about energy drinks is urgently needed. Policies for energy drinks consumption and smoking control programs are also recommended.
\end{abstract}

Keywords: energy drinks, prevalence, predictors, medical students

Cite This Article: Nahla Khamis Ragab Ibrahim, Rahila Iftikhar, Manal Murad, Hashim Fida, Bahaa Abalkhaeil, and Jawaher Al Ahmadi, "Energy Drinks Consumption amongst Medical Students and Interns from Three Colleges in Jeddah, Saudi Arabia." Journal of Food and Nutrition Research, vol. 2, no. 4 (2014): 174-179. doi: 10.12691/jfnr-2-4-7.

\section{Introduction}

Medical students are exposed to various stressors [1] that may precipitate a variety of health risk behaviors, such as smoking [2,3] and consumption of high levels of caffeinated beverages [4]. Energy drinks are fortified beverages with added nutritional supplements [5,6]. These beverages contain large doses of methylxanthines (including caffeine) and other stimulants such as taurine, carbohydrates, glucuronolactone, inositol, niacin, panthenol, and B-complex vitamins and herbs. Hundreds of different brands on the market have high caffeine content, ranging from a modest $50 \mathrm{mg}$ to an alarming 505 mg per can or bottle. The marketing of these drinks relies chiefly on that the natural ingredients in energy drinks supply may increase energy, alertness, improve athletic performance and concentration time [7,8,9,10].

On the other hand, many reported adverse events of acute caffeine intoxication pose serious threats to public health. These include myocardial infarction, behavioral disorder, neuro-psychosis, seizure, coma, weight gain and disorders of the gastrointestinal, renal and musculoskeletal systems, etc $[8,10,11,12]$. Furthermore, some reports of unexpected deaths among apparently healthy persons have been associated with consumption of caffeinated beverages [13]. All these adverse effects raise the needs for closer scrutiny and possible regulation.

Researchers have indicated that as a result of lack of restrictions, energy drinks are aggressively marketed, appealing especially among young males seeking performance enhancement and other stimulant-related effects $[7,10]$. 
Energy drink consumption has become widespread among college students [14] and also is considered an emerging health risk behavior among students at Saudi Universities [4,10]. However, only limited number of research studies has been conducted to determine energy drink usage among college students. There are also little researches done on energy drink consumption patterns among medical students. In addition, there is no adequate data that report the associated factors of energy drink consumption. Thus, such study is urgently needed.

The objective of the present study was to determine the prevalence, pattern and predictors of energy drink consumption among medical students and interns in three medical colleges, Jeddah, Saudi Arabia.

\section{Materials and Methods}

A cross- sectional study was conducted during 2013 among medical students and interns at three medical colleges in Jeddah, Kingdom of Saudi Arabia (KSA). These colleges are the governmental college of King Abdulaziz University (KAU) and the two private colleges of Ibn-Sina and Al- Battargi Medical Ccolleges.

Ethical statement: The study was approved by the Institutional Review Board (IRB) of Faculty of Medicine, King Abdulaziz University (Reference No. 1288-13) and conformed to the ethical standards of the Helsinki declaration. The team followed the ethical standards of confidentiality and freedom of participation. During field work, a written informed consent was requested from each student and intern prior to participation. Administrative approvals were taken from deans of the three colleges.

A multistage stratified random sampling technique was used to select the participants. Eligible subjects were medical students who completed the freshman year (from $2^{\text {nd }}-6^{\text {th }}$ year) and the interns from the 3 colleges, who accepted to participate. Stratification put into consideration the type of college, gender \& grade of participant.

The sample size was calculated according to the following established formula for sample size determination [15]:

$$
n=\frac{z^{2} \times p \times q}{d^{2}}
$$

$\mathrm{n}$ : the minimum sample size, $\mathrm{Z}=$ constant (1.96). As there is no recent study about the prevalence among medical students and interns in Jeddah, we assumed the prevalence of use of energy drink is $50 \%$ as the most conservative sample.

So, $\mathrm{p}=0.5 \& \mathrm{q}=1-\mathrm{P}=0.5$.

Hence, the sample size to achieve a precision of $\pm 4 \%$ with a $95 \%$ Confidence Interval (CI) was 600 which was exceeded for stratification purposes during the field work to reach 610 .

A validated, constructed, anonymous, confidential \& self-administered questionnaire was used. Reliability of the questionnaire was assessed using Cronbach's $\alpha$ test and it was found to be $87 \%$. The questionnaire inquired about personal, socio-demographic characteristics, history of previous health problems and history of other habits as smoking. History of ever use, inspiration of starting energy drinks, regular use during the two months preceded the study, frequency of use, the cause of selecting energy drinks and any reported adverse effects were also inquired.

Statistical analysis: Data analysis was done using the statistical package SPSS version 21. (SPSS Inc, Chicago, Ill). Descriptive statistics are expressed as frequencies, percentages and as mean \pm standard deviation (SD). Chisquare $\left(X^{2}\right)$ test was used to compare between categorical variables. Student's t -test was used to compare between 2 independent means. Odds Ratio (OR) and 95\% Confidence Intervals (CI) were calculated. For controlling confounding factors, a logistic regression analysis was used to determine the predictors of energy drink consumption. A $p$-value $<0$. 05 was considered statistically significant.

\section{Results}

The study included 610 medical students and interns from the 3 colleges. Their age ranged from 18-28 years with a mean of $22.2 \pm 2.1$ years. Students from KAU represented $62.1 \%$, while those from private college were $37.9 \%$ of the sample. The male: female ratio was 1.3:1.

The mean age of starting energy drinks was $16.89 \pm$ 3.08 years among the participants. Males started at younger age $(16.10 \pm 2.86$ years) compared to females (18.31 \pm 2.98 years). A highly statistical significant difference was present (Student's t -test $=4.76, p<0.001$ )

Table 1 reveals that more than one-half $(52.7 \%)$ of the medical students \& interns had "ever" tried energy drinks. The main inspirations of the first use of energy drinks, among ever users, were friends (50.2\%), advertisement (31.4\%) and curiosity (18.4\%). The table also shows that that the prevalence of regular consumption of energy drinks during the 2 months preceded the study was $33.4 \%$. It is also apparent from the table that the prevalence of current smoking among participants was $17.8 \%$.

Figure 1 illustrates the causes of choosing such drinks among regular users during the last 2 months. Enjoying leisure time with friends (57.5\%), boosting energy for studying (56.4\%), staying awake for a long time (50.5\%), driving for long distance (33.8\%) and better athletic performance $(24.5 \%)$ were the most common reasons, from their opinions.

Table 1. Energy drink \& smoking habits among medical students and interns in the three Jeddah collages

\begin{tabular}{|l|c|c|}
\hline Item & No. & $\%$ \\
\hline Ever use energy drinks & 321 & 52.6 \\
\hline Yes & 289 & 46.4 \\
\hline No (Never use) & 161 & 50.2 \\
\hline Inspiration for the first use of energy drink among ever users \\
\hline Friends & 59 & 31.4 \\
\hline Advertisement & 101 & 18.4 \\
\hline Curiosity (wondering about taste) & 321 & 100 \\
\hline Total & 204 & 33.4 \\
\hline Use of energy drink during the two months preceded the study \\
\hline Yes & 406 & 66.6 \\
\hline No & 109 & 17.8 \\
\hline Smoking & 501 & 82.2 \\
\hline Yes
\end{tabular}




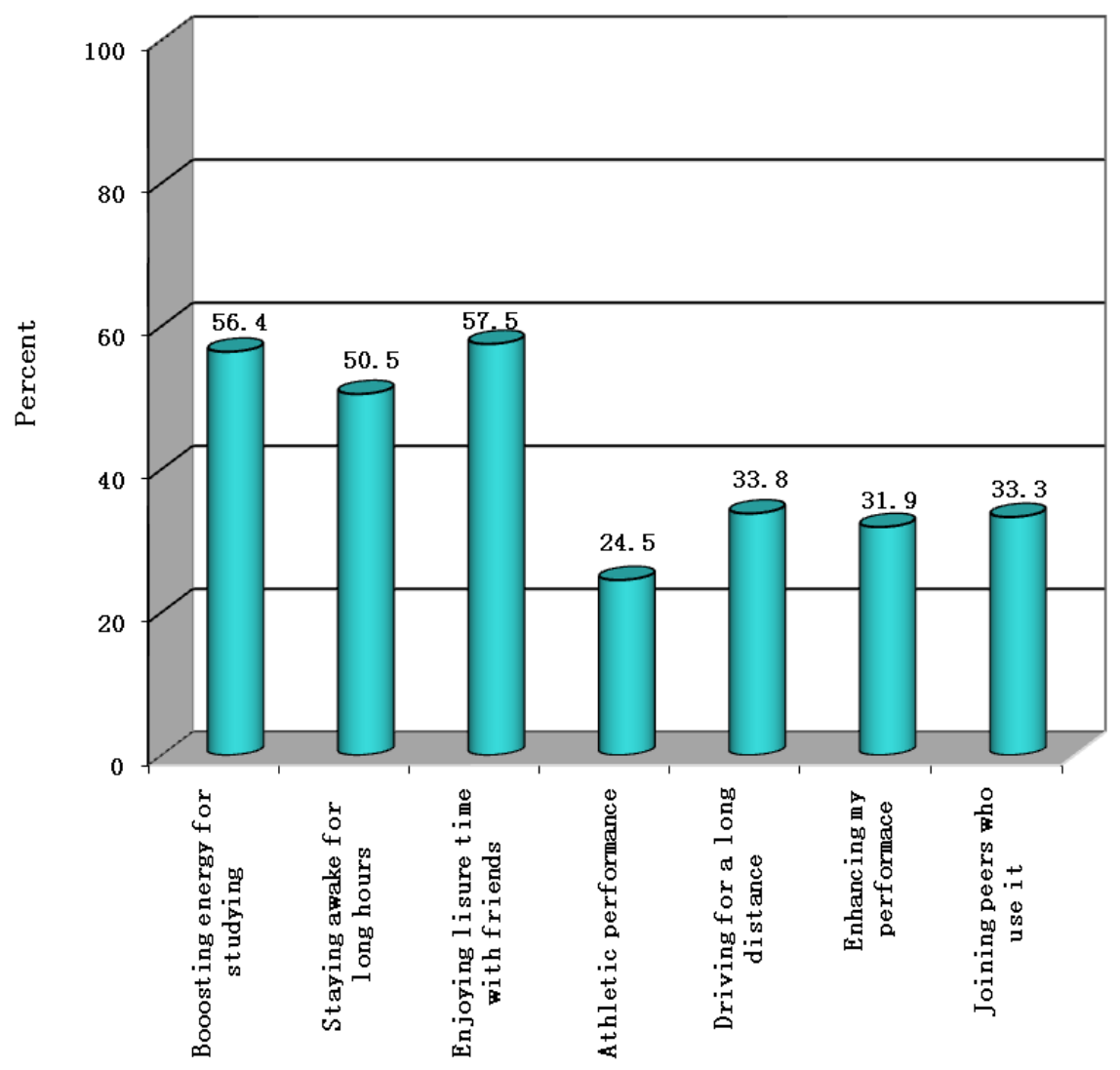

Figure 1. Causes of energy drinks consumption according to opinions of medical students and interns at three medical colleges in Jeddah (N.B. Each question is separately asked)

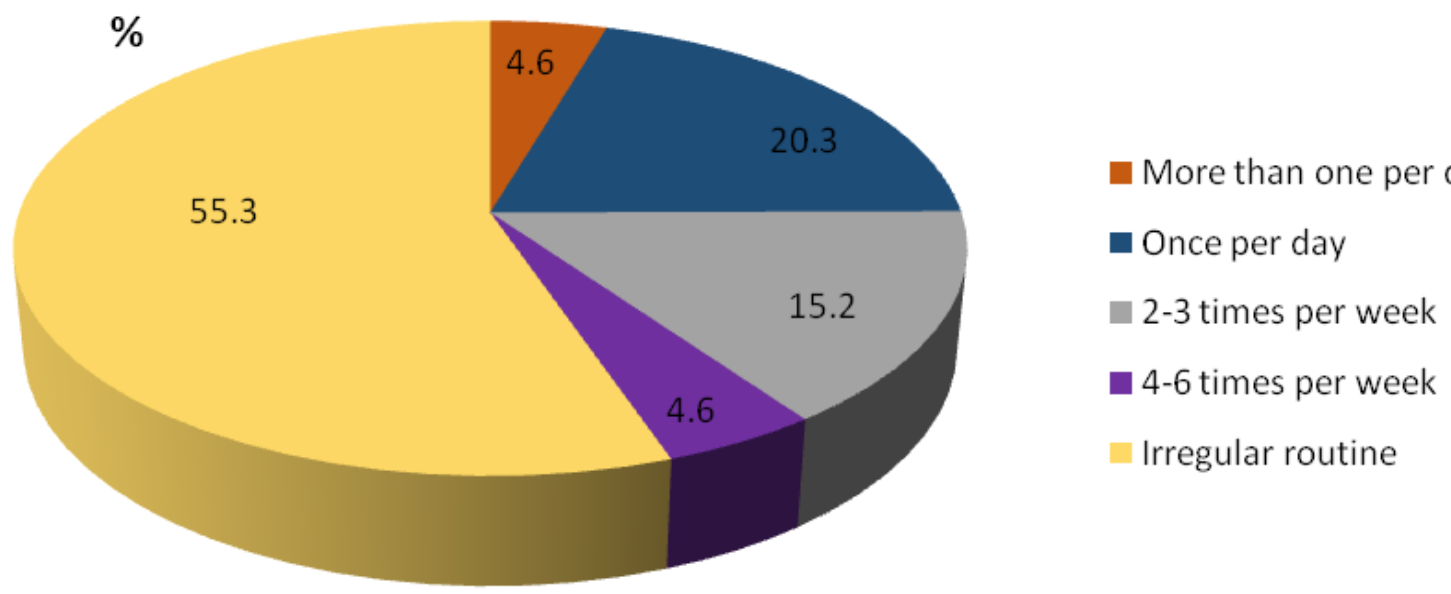

Figure 2. Frequency of energy drinks consumption among medical students and interns use it during the two months preceded the study

The frequency of using energy drinks among those who consumed energy drinks during the 2 months preceded the study is illustrated in Figure 1. It is apparent from the figure that $4.6 \%$ of regular users consumed energy drinks more than once daily, about one- fifth (20.3\%) utilized it on a daily base, while $15.2 \%$ used these drinks for 2-3 times / week.

About one -third (31.6\%) of regular users of energy drinks reported experiencing adverse effects after using of such drinks. Heart palpitation was most commonly reported side effect (30.4\%) followed by insomnia (29.5\%), frequent micturition (19.1\%), headache (16.2\%) and Jolt and crash episodes (4.8\%).

Table 2 shows the relationship between energy drink consumption (among regular users) and the studied variables. Energy drink consumption was significantly higher among males (37.6\%) compared to females
(27.9\%). (OR =1.56; $95 \% \mathrm{CI}: 1.11-2.2)$. Students enrolled in private collages had higher odds of energy drink consumption than those from the KAU governmental college, with a statistical significant difference $\left(X^{2}=4.32\right.$, $p<0.05)$. Prevalence of energy drink consumption was also much higher among smokers (59.6\%) compared to non-smokers (27.1\%), with a highly statistical significant difference $\left(X^{2}=42.15, p<0.001\right)$. Furthermore, energy drink consumption was lower among Saudis (32.3\%) compared to non-Saudis (38.9\%). However, there is no statistical significant difference $(p>0.05)$.

After controlling confounding factors in logistic regression, the only predictor of energy-drink consumption during the 2 months proceeded the study was smoking $(\mathrm{aOR}=3.68 ; 95 \% \mathrm{CI}: 2.36-5.71)$ as shown in Table 3. 
Table 2. Relationship between regular energy drinks consumption and the studied variables among medical students and interns from the three colleges in Jeddah

\begin{tabular}{|c|c|c|c|c|c|}
\hline \multirow{2}{*}{ Variables } & \multicolumn{2}{|c|}{ Energy drink consumption } & \multirow{2}{*}{ Total } & \multirow{2}{*}{$X^{2}(p)$} & \multirow[b]{2}{*}{ OR (CI) } \\
\hline & Yes (\%) & No (\%) & & & \\
\hline \multicolumn{4}{|l|}{ Gender } & \multirow{3}{*}{$6.42(0.01)$} & \multirow{3}{*}{$1.56(1.11-2.20)$} \\
\hline Male & 131 (37.6) & $217(62.4)$ & 348 & & \\
\hline Female & $73(27.9)$ & $189(72.1)$ & 262 & & \\
\hline \multicolumn{4}{|l|}{ Age (years) } & \multirow{3}{*}{$0.38(0.53)$} & \multirow{3}{*}{$0.87(0.56-1.35)$} \\
\hline$<21$ & $35(31.0)$ & $78(69.0)$ & 113 & & \\
\hline$\geq 21$ & $169(34.0)$ & $328(66.0)$ & 497 & & \\
\hline \multicolumn{4}{|l|}{ Nationality } & \multirow{3}{*}{$1.74(0.19)$} & \multirow{3}{*}{$0.75(0.49-1.15)$} \\
\hline Saudi & $162(32.3)$ & $340(67.7)$ & 502 & & \\
\hline Non-Saudi & $42(38.9)$ & $66(61.1)$ & 108 & & \\
\hline \multicolumn{6}{|l|}{ Marital status } \\
\hline Single & $186(33.1)$ & $376(66.9)$ & 562 & \multirow{2}{*}{$0.39(0.54)$} & \multirow{2}{*}{$0.82(0.45-1.52)$} \\
\hline Married & $18(37.5)$ & $30(62.5)$ & 48 & & \\
\hline \multicolumn{6}{|l|}{ Education } \\
\hline Basic \& clinical years & $190(32.2)$ & $382(66.8)$ & 572 & \multirow{2}{*}{$0.21(0.65)$} & \multirow{2}{*}{$0.85(0.43-1.69)$} \\
\hline Interns & $14(36.8)$ & $24(63.2)$ & 38 & & \\
\hline \multicolumn{6}{|l|}{ Father's Education } \\
\hline$<$ university & $50(31.6)$ & $108(68.4)$ & 158 & \multirow{2}{*}{$0.31(0.58)$} & \multirow{2}{*}{$0.89(0.61-1.32)$} \\
\hline University \& above & $154(34.1)$ & $298(65.9)$ & 452 & & \\
\hline \multicolumn{6}{|l|}{ Mother's Education } \\
\hline$<$ university & $83(31.4)$ & $181(68.6)$ & 264 & 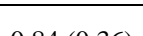 & $00-10 C 1110$ \\
\hline University \& above & $121(35.0)$ & $225(65.0)$ & 346 & $0.84(0.36)$ & $0.85(0.61-1.19)$ \\
\hline Father's occupation & & & & & \\
\hline Professional & $147(35.1)$ & $272(64.9)$ & 419 & 1.62 & 1.27 \\
\hline Non professional & $57(29.8)$ & $134(70.2)$ & 191 & $(0.20)$ & $(0.88-1.83)$ \\
\hline Mother's occupation & & & & & \\
\hline Professional & $106(31.8)$ & $227(58.2)$ & 333 & 0.86 & 0.85 \\
\hline Non professional & $98(35.4)$ & $179(64.6)$ & 277 & $(0.36)$ & $(0.61-1.20)$ \\
\hline Parent's Living & & & & & \\
\hline Living together & $181(33.5)$ & $359(66.5)$ & 540 & 0.01 & 0.1 .03 \\
\hline Not living together & $23(32.9)$ & $47(67.1)$ & 70 & $(0.91)$ & $(0.61-1.75)$ \\
\hline Institute & & & & & \\
\hline Government (KAU) & $115(30.3)$ & $264(69.7)$ & 379 & 4.32 & 0.70 \\
\hline Private & 119 (51.5) & $112(48.5)$ & 231 & $(0.03)$ & $(0.49-0.98)$ \\
\hline Resident & & & & & \\
\hline With family & $168(33.3)$ & 337 (66.7) & 505 & 0.04 & 0.96 \\
\hline Without family & $54(51.4)$ & $51(48.6)$ & 105 & $(0.84)$ & $(0.61-1.49)$ \\
\hline Smoking & & & & & \\
\hline Yes & 65 (59.6) & $44(40.4)$ & 109 & 42.15 & 4.0 \\
\hline No & $125(27.1)$ & $337(72.9)$ & 462 & $(0.000)$ & $(2.58-6.15)$ \\
\hline Health problem & & & & & \\
\hline Yes & $21(36.8)$ & $36(63.2)$ & 57 & 0.33 & 1.18 \\
\hline No & $125(27.1)$ & 337 (72.9) & 553 & $(0.56)$ & $(0.66-2.08)$ \\
\hline
\end{tabular}

Table 3. Logistic regression analysis of predictor of energy drink consumption among medical students and interns in the three medical colleges of Jeddah

\begin{tabular}{|c|c|c|c|c|}
\hline Variables & $\beta$ & $p$ & $\mathrm{aOR}$ & CI \\
\hline Smoking & 1.302 & 0.000 & \multirow{2}{*}{3.68} & \multirow{2}{*}{$2.36-5.71$} \\
Constant & -1.5 & 0.000 & & \\
\hline
\end{tabular}

aOR: Adjusted odds ratio

CI: Confidence interval

\section{Discussion}

Energy drinks are emerging as a public health threat while its market has grown exponentially over the past decade, with increasing consumption by youth internationally $[7,16]$. Generally, this is apparent from results of the current study which demonstrated that energy drink consumption is a common practice among medical students and interns in Jeddah colleges. More than one-half of participants had ever tried energy drinks. This high rate may be found because college students have hard schedules and can be under a great amount of stress. One way students think for fighting this problem is by consuming energy drinks to get that much needed boost of energy [17]. Our result is higher than Bulut, et al, 2014, who conducted a study at the Karadeniz Technical University in Turkey and found that $46.5 \%$ of students had ever tried energy drinks [18].

The prevalence of regular consumption of energy drinks during the 2 months preceded the study was 33.4\%. This rate is considered a high rate. It is higher than other two studies; one study among the first \& second year medical students in Puerto Rico where the prevalence of use was 29\% [19] and the second among 257 medical students enrolled in Umm Al-Qura governmental University, Makkah, KSA where the rate was 27.2\% [4]. The cause of discrepancy between the current and the Puerto Rican study may be attributed to differences in the educational grades of participants. While, the inconsistency between our study and Umm Al-Qura may be due to differences in sample size, or may be because their study was done among students from governmental college only. On the other hand, Alsunni and Bader reported a higher prevalence (45.6\%) among 410 students in Dammam, KSA (a prevalence of $54.60 \%$ and $26.15 \%$ among males and females, respectively)[10]. This difference may be because the Dammam's study was conducted among students from all faculties not only among medical students, or may be because the number of 
males in their study was much higher than females (their male: female ratio was about 2.1:1) with a higher prevalence among males, or may attributed to differences in both sample sizes. Similarly another study conducted at four medical colleges in Karachi, Pakistan reported a higher rate $(42.9 \%)$ of energy drinks consumption among medical students than that reported from our study [8].

Our finding showed that the age at first use of energy drink was around 16 years which agrees with results of Alsunni and Bader from Dammam [10]. This can be seen as a young age for starting energy drinks usage. Furthermore, the current study showed that the age at start was significantly younger among males compared to the females which disagree with results from Dammam study.

Our results showed that friends, advertisement and curiosity were the commonest inspiration for starting energy drinks. This result showed the big effect of friends which agrees also with other studies $[10,18,20]$. The high percentage of students influenced by advertisement may be because these companies spend a lot of money for promotion of such drinks [10].

Energy drinks are advertized for their stimulatory effect and for claims of giving benefits as physical endurance reaction, concentration, reduce sleep and promote athletic performance. This agrees with our findings and with the results of a previous study [8]. In our study enjoying leisure time with friends, boosting energy for studying, staying awake for a long time were the most common reasons for consumption from the opinion of the participants. Another survey done among college students in the Central Atlantic region of the United States found that the majority of users consumed energy drinks to increase energy which agrees with the current study [21].

The present results revealed that energy drink consumption was significantly higher among males compared to females. This finding agrees with results of many other studies $[10,11,18,19,22]$. A reason that can be given for the higher intake of energy drinks among males may be because Saudi females are less practicing physical activity than males and energy drinks are mostly marketed for increasing physical performance [8]. Miller [12,21] also asserted that advertisements of energy drinks usually target primarily young adult males or because energy drink may enable males appear more masculine.

In regression analysis, the only predictor of energy drink consumption in the current study was smoking. This result is in line with results of two recent Canadian studies and with a Turkish study [23,24,25]. Miller [12] also reported that energy drink was associated with smoking among undergraduate students from Western New York, the United States. The association of energy drinks with other potential negative health and behavioral outcomes suggests that use of these products may represent a marker for other activities that may negatively affect adolescent development, health and well-being [23,24].

The current study revealed a high rate of reported side effects of energy drinks. The most commonly occurred adverse effects were palpitation, insomnia, frequent micturition, headache and Jolt and crash episodes which in line with many other researchers $[8,16,26,27]$. The cause of frequent micturition may be because caffeine acts as a diuretic agent and as such causes the kidneys to remove extra fluid from the body [21]. Regarding insomnia, the American College Health Association reported that college students suffered from insufficient sleep and not feeling rested for at least five of the seven days preceded the study [28].

\section{Conclusion}

Energy drinks are fortified beverages with added nutritional supplements. Their marketing relies mainly on that the natural ingredients in energy drinks supply may increase energy, alertness, improve athletic performance and concentration time. On the other hand, many reported adverse events of acute caffeine intoxication pose serious threats occurs due to their consumption. Energy drinks have become increasingly popular among adolescents and young adults in recent years. In the current study, the practice of consuming energy drinks was highly prevalent among medical students and interns from the three medical colleges in Jeddah, KSA. More than one-half of the participants (52.6\%) in the study had "ever" tried energy drinks, while 33.4\% consumed it regularly during the two months preceded the study. This high prevalence rates among participants occurred despite of the high prevalence of reported side effects as palpitation (30.4\%), insomnia (29.5\%), frequent micturition (19.1\%), headache (16.2\%) and Jolt \& crash episodes (4.8\%).

This is particularly may be because the participants in the current work saw these drinks as a drink ready to boost their energy level and reduce sleep hours for studying due to stress of medical exams. Energy drink consumption started around 16 years which is considered a young starting age. Smoking was significantly associated with higher odds of being an energy drink consumer.

Friends, advertisement and curiosity were the inspirations for starting. Among regular users, the commonest reasons for consumption were enjoying leisure time with friends (57.5\%), boosting energy for studying (56.4\%), and staying awake for long hours (50.5\%).

It will be useful for these factors listed above to be borne in mind in the development of policies aimed at protecting young people from the health impacts and side effects of energy drinks. This warrant importance of creation of continued public health awareness, especially among medical students, about the appropriate use of caffeinated beverages, their potential benefits, side effects and correction of wrong perceptions. Media campaigns are needed for raising awareness about the potential harms of excessive energy drinks for young adults particularly young males. This might include television and other source of advertisements. Guidelines should be put in place to ensure that advertising and promotion of energy drinks have reasonable limits and controls to minimize the risk of rapid, excessive or irresponsible consumption of these drinks. Energy drinks policies and conduction of smoking control programs is also recommended.

\section{Acknowledgment}

The authors would like to thank all medical students and interns from the three medical colleges who participated in the study. Special thanks to Dr. Mehenaz Hanbazazh, a pathology demonstrator, at King Abdulaziz University (North Jeddah Branch) and Abdullah Khalid Sagga a student at the Battargi Medical College for their 
efforts during data collection phase of the study. We would like to thank also all administrators from the three colleges for facilitating conduction of the study.

\section{Conflict of Interest and Funding}

The authors have no conflict of interest to report. There also was no funding.

\section{List of Abbreviations}

$\begin{array}{ll}\text { Full name } & \text { Abbreviation } \\ \text { King Abdulaziz University } & \text { KAU } \\ \text { Kingdom of Saudi Arabia } & \text { KSA } \\ \text { Odds Ratio } & \text { OR } \\ \text { Chi-square } & X^{2} \\ \text { Confidence Intervals } & \text { CI } \\ \text { Standard Deviation } & \text { SD } \\ \text { Adjusted Odds Ratio } & \text { aOR }\end{array}$

\section{References}

[1] Ibrahim N, Al- Kharboush D, El-Khatib L, Al -Habib A, Asali D. Prevalence and predictors of anxiety and depression among female medical students in King Abdulaziz University, Jeddah, Saudi Arabia. Iranian Journal of Public Health 2013; 42 (7): 726-736.

[2] Al-Turki YA. Smoking habits among medical students in Central Saudi Arabia. Saudi Med J. 2006; 27: 700-3.

[3] Abdulghani HM, Alrowais NA, Alhaqwi AI, Alrasheedi A, AlZahir M, Al-Madani A, Al-Eissa A, Al-Hakmi B, Takroni R, Ahmad F. Cigarette smoking among female students in five medical and nonmedical colleges. Int J Gen Med 2013; 6: 719-27.

[4] Bawazeer NA, AlSobahi NA. Prevalence and Side Effects of Energy Drink Consumption among Medical Students at Umm AlQura University, Saudi Arabia. The International Journal of Medical Students 2013; 1 (3): 104-108.

[5] Clauson KA, Shields KM, McQueen CE, Persad N. Safety issues associated with commercially available energy drinks. J Am Pharm Assoc (2003) 2008; 48 (3): e55-63; quiz e64-7.

[6] McGraw MM. Are energy drinks safe? Nursing 2013; 43 (3): 68.

[7] Reissig CJ, Strain EC, Griffiths RR. Caffeinated energy drinks--a growing problem. Drug Alcohol Depend 2009; 99 (1-3): 1-10.

[8] Aslam HM, Mughal A, Edhi MM, Saleem S, Rao MH, Aftab A, Hanif M, Ahmed A, Khan AM. Assessment of pattern for consumption and awareness regarding energy drinks among medical students. Arch Public Health 2013; 71 (1): 31.

[9] Kamran B. Consumption's Pattern and Knowledge of Athletes about Energy Drink in South of Iran (Shiraz). Journal of Nutrition \& Food Sciences 2012; 2 (3): 1-7.

[10] Alsunni AA, Badar A. Energy drinks consumption pattern, perceived benefits and associated adverse effects amongst students of University of Dammam, Saudi Arabia. J Ayub Med Coll Abbottabad 2011; 23 (3): 3-9.

[11] Babu KM, Zuckerman MD, Cherkes JK, Hack JB. First-Onset Seizure After Use of an Energy Drink [corrected]. Pediatr Emerg Care 2011; 27 (6): 539-40.

[12] Miller KE. Energy drinks, race, and problem behaviors among college students. J Adolesc Health 2008; 43 (5): 490-7.

[13] Sepkowitz KA. Energy drinks and caffeine-related adverse effects. Jama 2013; 309 (3): 243-4.

[14] Oteri A, Salvo F, Caputi AP, Calapai G. Intake of energy drinks in association with alcoholic beverages in a cohort of students of the School of Medicine of the University of Messina. Alcohol Clin Exp Res 2007; 31 (10): 1677-80.

[15] Wang W. Clinical Epidemiology-Basic Principles and Practical Applications, 2012, 101, Beijing.

[16] Pomeranz JL, Munsell CR, Harris JL. Energy drinks: an emerging public health hazard for youth. J Public Health Policy 2013; 34 (2): 254-71.

[17] Bliss TJ, Depperschmidt CL. Energy Drink Consumption and its Effects on Student Pilots: Perceptions of Collegiate Flight Students. Collegiate Aviation Review 2011; 29 (2).

[18] Bulut B, Beyhun NE, Topbas M, Can G. Energy Drink Use in University Students and Associated Factors. J Community Health 2014.

[19] Rios JL, Betancourt J, Pagan I, Fabian C, Cruz SY, Gonzalez AM, Gonzalez MJ, Rivera-Soto WT, Palacios C. Caffeinated-beverage consumption and its association with socio-demographic characteristics and self-perceived academic stress in first and second year students at the University of Puerto Rico Medical Sciences Campus (UPR-MSC). P R Health Sci J 2013;3 2 (2): 95100.

[20] Attila S, Çakir B. Energy-drink consumption in college students and associated factors. Nutrition 2011; 27 (3): 316-22.

[21] Buxton C, Hagan JE. A survey of energy drinks consumption practices among student -athletes in Ghana: lessons for developing health education intervention programmes. J Int Soc Sports Nutr 2012; 9 (1): 9.

[22] Wimer DJ, Levant RF. Energy Drink Use and Its Relationship to Masculinity, Jock Identity, and Fraternity Membership Among Men. Am J Mens Health 2013.

[23] Azagba S, Sharaf MF. Is alcohol mixed with energy drinks consumption associated with susceptibility to smoking? Prev Med 2014.

[24] Azagba S, Langille D, Asbridge M. An emerging adolescent health risk: Caffeinated energy drink consumption patterns among high school students. Prev Med 2014; 62 c: 54-59.

[25] Hidiroglu S, Tanriover O, Unaldi S, Sulun S, Karavus M. A survey of energy-drink consumption among medical students. $J$ Pak Med Assoc 2013; 63 (7): 842-5.

[26] Malinauskas BM, Aeby VG, Overton RF, Carpenter-Aeby T, Barber-Heidal K. A survey of energy drink consumption patterns among college students. Nutr J 2007; 6: 35.

[27] Gunja N, Brown JA. Energy drinks: health risks and toxicity. Med J Aust 2012; 196 (1):46-9.

[28] Hoban M. American College Health Association National College Health Assessment spring 2006 reference group data report (abridged). Journal of American College Health 2007. 